\title{
Effects of nitrogen, phosphorus, EDTA and sodium chloride on biomass and lipid accumulation of Chaetomorpha aerea
}

\author{
Gour Gopal Satpati'*, Ruma Pal² \\ 'Department of Botany, Bangabasi Evening College, University of Calcutta, 19 Rajkumar Chakraborty Sarani, \\ Kolkata-700009, West Bengal, India, ${ }^{2}$ Phycology Laboratory, Department of Botany, Centre of Advanced Study \\ (CAS), University of Calcutta, 35 Ballygunge Circular Road, Kolkata-700019, West Bengal, India
}

Received: June 29, 2020 Revised: August 23, 2020 Accepted: August 26, 2020 Published: September 05, 202

*Corresponding Author: Gour Gopal Satpati Email: gour_satpati@yahoo. co.in

\begin{abstract}
The increase of total lipid and fatty acids production was studied under different nutrient stress conditions using the macroalga Chaetomorpha aerea. The effects of nitrogen, phosphorus, ethylene diamine tetra-acetate and sodium chloride on the growth and lipid accumulation were systematically investigated in laboratory conditions. The biomass was harvested at different stages of cultivation and assessed. The maximum changes of growth and lipid accumulation were observed in the exponential phase at different cultural conditions. The two-fold increase of total lipid was found in the order of $28.27 \pm 0.04 \%$ (at $0.1 \mathrm{~g} / \mathrm{L}$ nitrogen) $>27.30 \pm 0.37 \%$ (at $0.5 \mathrm{~g} / \mathrm{L}$ of phosphorus) $>25.86 \pm 0.77 \%$ (at $0.05 \mathrm{~g} / \mathrm{L}$ of EDTA) $>24.37 \pm 0.04 \%$ (at $0.05 \mathrm{~g} / \mathrm{L} \mathrm{NaCl}$ ) on $8^{\text {th }}$ day of cultivation. The fatty acids were identified and quantified by gas chromatography mass spectrometry (GC-MS). The alga produces significantly high amount of monounsaturated fatty acid (MUFA) and saturated fatty acids (SFA) than the polyunsaturated fatty acids (PUFA) in different cultural conditions. The elevated levels of C16:1, C18:1 and C20:1 was identified under nitrate, phosphate and salt stress conditions, which are more suitable for biodiesel production.
\end{abstract}

KEYWORDS: Biodiesel, Chaetomorpha aerea, FAME, lipid, nutrient, stress

\section{INTRODUCTION}

Nutrients are most widely used environmental factors used to stimulate the biochemical changes in algae and other plant communities. The light energy is converted to chemical energy in the form of carbohydrates, lipids and other bioactive compounds. From the past few decades microalgae are being considered as the most promising agent for lipid production technology.

Marine seaweeds or macroalgae are the excellent source of bioactive compounds like proteins, vitamins, carotenoids, dietary fibres and essential fatty acids. These essential fatty acids include both the saturated and unsaturated form. The lipid content of marine macroalgae is very low $(1-5 \%)$ but under stress conditions they produce up to $30-40 \%$ [1]. The fatty acids of marine macroalgae generally have linear chains and even number of carbon atoms with one or more double bonds [2]. Macroalgae have been studied for long for the production of wide range of natural chemicals like agar, agarose, carrageenan and alginates. However, they have never been looked for lipids, as energy resource [1]. Microalgae have been considered for high lipid and used for biodiesel application several times [3-6]. Stress induced changes in lipid and fatty acids profile have also been discussed for long [7-11]. But very few reports are available on macroalgal lipid and fatty acids [12-14]. The effect of nitrate and phosphates on lipidomic and other biochemical compositions of the macroalga Ulva lactuca were studied by Kumari et al. [15]. They investigated the changes in polar lipids, chlorophyll and protein content when they cultured the alga in artificial sea nutrient (ASW) medium supplemented with nitrate and phosphate. Biochemical composition of eighteen marine macroalgae belonging to Chlorophyta, Phaeophyta and Rhodophyta were studied from Okha coast, Gulf of Kutch, India [16]. They studied varied quantities of bioactive compounds like total lipid, protein, carbohydrate, phenol and amino acids. Seasonal variations in fatty acid compositions of 51 macroalgae were studied from Gulf of Mannar, Marine Biosphere Reserve of Southeast coast of India [17]. Comparative accounts of fatty acid compositions of three marine macroalgae were also studied from the coastal region of South India [18]. In our previous study we have reported the effect of nutrient and other abiotic stresses on growth and lipid accumulation in Rhizoclonium africanum [13].

Copyright: $\odot$ The authors. This article is open access and licensed under the terms of the Creative Commons Attribution License (http:// creativecommons.org/licenses/by/4.o/) which permits unrestricted, use, distribution and reproduction in any medium, or format for any purpose, even commercially provided the work is properly cited. Attribution - You must give appropriate credit, provide a link to the license, and indicate if changes were made. 
The effects of different nutrient stresses such as nitrogen, phosphorus, ethylene diamine tetra-acetate (EDTA) and sodium chloride $(\mathrm{NaCl})$ on production of high lipid, saturated fatty acids (SFA), monounsaturated fatty acids (MUFA), polyunsaturated fatty acids (PUFA) in macroalgae has not been studied to date. In this study, our aim was to determine and compare the effects of different nutrient stresses on growth and lipid synthesis for biodiesel production from C. aerea.

\section{MATERIAL AND METHODS}

\section{Strain and Culture Condition}

C. aerea was collected from the coastal zone of Indian Sundarbans $\left(\mathrm{N} \mathrm{22}{ }^{\circ} 01.142, \mathrm{E} 088^{\circ} 40.955\right)$ and isolated and cultivated in modified Bold Basal Medium [19] (Figure 1). The compositions of the modified BBM media was manipulated as $\mathrm{NaNO}_{3}-0.25 \mathrm{~g} ; \mathrm{CaCl}_{2}$ $0.025 \mathrm{~g} ; \mathrm{MgSO}_{4} .7 \mathrm{H}_{2} \mathrm{O}-0.075 \mathrm{~g} ; \mathrm{K}_{2} \mathrm{HPO}_{4}-0.075 \mathrm{~g} ; \mathrm{KH}_{2} \mathrm{PO}_{4}-0.175 \mathrm{~g}$; Nacl-0.5 g and dissolved in $1000 \mathrm{ml}$ of double distilled water. The alga was grown at $20^{\circ} \mathrm{C}$ and 16:8 light-dark cycles with $135 \mathrm{rpm}$ agitation in Eyela horizontal shaker-incubator (Eyela, Japan).

\section{Measurement of Biomass Yield}

For measurement of biomass, three sets of cultures were harvested at 2-day interval for thirty days from the date of inoculation. For harvesting, the cultures were washed with deionized water and blotted well with blotting paper. After proper air-drying, the biomass was transferred to pre-weighed vials for oven drying at $70^{\circ} \mathrm{C}$ to get a constant dry weight. The

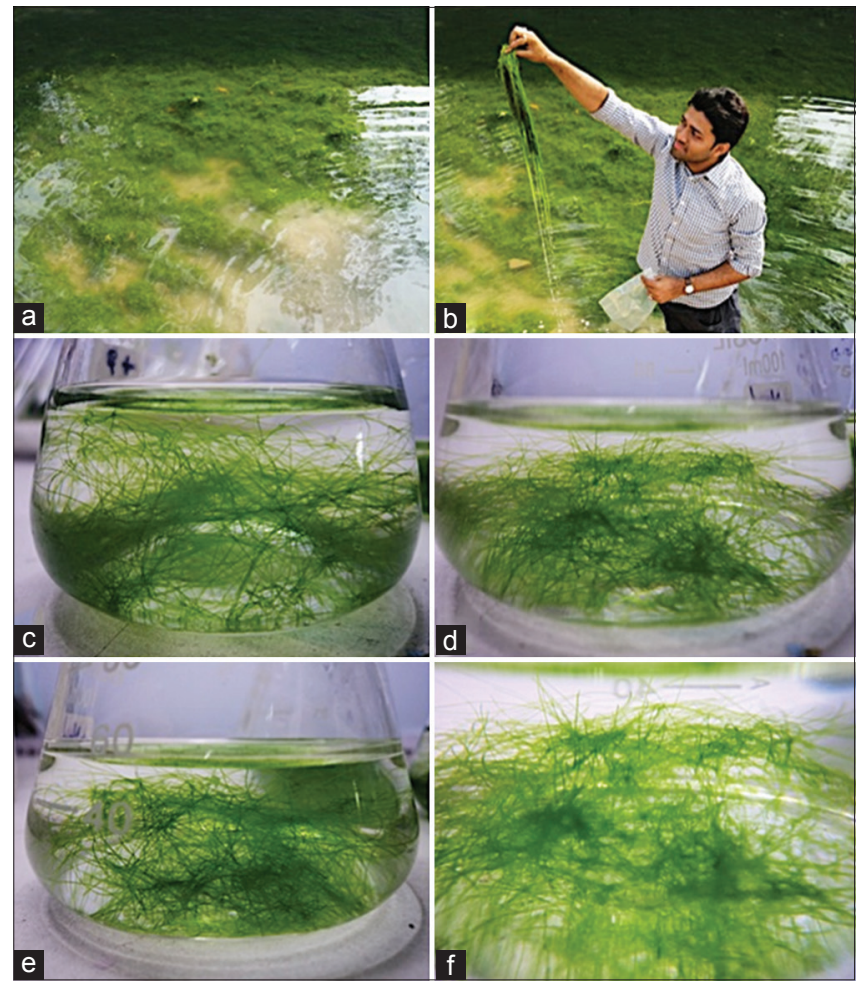

Figure 1: $a-b) C$. aerea collection from sampling site, c) Nitrogen induced culture, d) Phosphorus induced culture, e) EDTA induced culture, f) $\mathrm{NaCl}$ induced culture gravimetric method was applied to calculate the biomass in terms of $\mathrm{g} / \mathrm{L}[\mathrm{l}]$.

\section{Gravimetric Determination of Total Lipid}

About $0.5 \mathrm{~g}$ of dry algal biomass was taken and ground in mortar and pestle. The powdered sample was taken and mixed with $2 \mathrm{ml}$ of chloroform and $\mathrm{lml}$ of methanol [20]. The mixture was vortexed for 2-3 minutes and centrifuged at $8000 \mathrm{~g}$ for 5 minutes at $20^{\circ} \mathrm{C}$. Chloroform layer was collected carefully. The process was repeated 2-3 times and all the collected chloroform was mixed together and evaporated using rotary evaporator at room temperature. After getting the lipid residue, it was dried in oven at $60^{\circ} \mathrm{C}$ and weighed with electronic balance.

$\%$ of lipid in dry biomass $=$ final weight of the lipid sample after drying/ weight of the dry biomass $\times 100$

\section{Preparation of Fatty Acid Methyl Ester (FAME)}

Transesterification method was used to prepare fatty acid methyl esters. After extraction, the lipid samples were taken in a $10 \mathrm{ml}$ screw-cap borosil glass tube and transesterification reagent methanolic hydrochloric acid $(1: 4 \mathrm{v} / \mathrm{v})$ was added. The solution was then kept in a borosil glass beaker containing double distilled water and heated for $6-8$ hours at $70^{\circ} \mathrm{C}$. The solution was then cooled down and to avoid particulate matters it was centrifuged at 10,000 rpm for 10 minutes. The FAME extract was then transferred to Gas chromatography-mass spectrometry (GC-MS) auto-sample vials for analysis [11].

\section{Gas Chromatography Mass Spectrometry (GC-MS) Analysis}

GC-MS analysis was performed using FAME and detection was made with an Agilent 6890N Gas Chromatograph connected to an Agilent 5973 Mass Selective Detector at $70 \mathrm{eV}$ $\left(\mathrm{m} / \mathrm{z} 50-550\right.$; source at $230^{\circ} \mathrm{C}$ and quadruple at $\left.150^{\circ} \mathrm{C}\right)$ in the electron impact mode with a HP-5 ms capillary column $(30 \mathrm{~m}$ $\times 0.25 \mathrm{~mm}$ i.d. $\times 0.25 \mu \mathrm{m}$ film thickness). The temperature of the oven was set at $160^{\circ} \mathrm{C}$ for $2 \mathrm{~min}$ and then increased by $5^{\circ} \mathrm{C} / \mathrm{min}$ to $300^{\circ} \mathrm{C}$. The flow rate of the carrier gas (helium) was set to $1.0 \mathrm{~mL} / \mathrm{min}$. With split ratio of $50: 1$, the inlet temperature was maintained at $300^{\circ} \mathrm{C}$. Mass spectrometric fragmentation was used to determine structural assignments. It was confirmed by comparing fragmentation patterns and retention times of authentic compounds. On the basis of retention time identification of individual fatty acids was done [12-13].

\section{Statistical Analysis}

Statistical analysis was performed in triplicate $(n=3)$ and data expressed as mean \pm standard deviation (SD) with standard error (SE) bars. Significant differences $(p<0.05)$ between means in terms of biomass, lipid and fatty acids were obtained through one-way analysis of variance (ANOVA) and Tukey's test. 


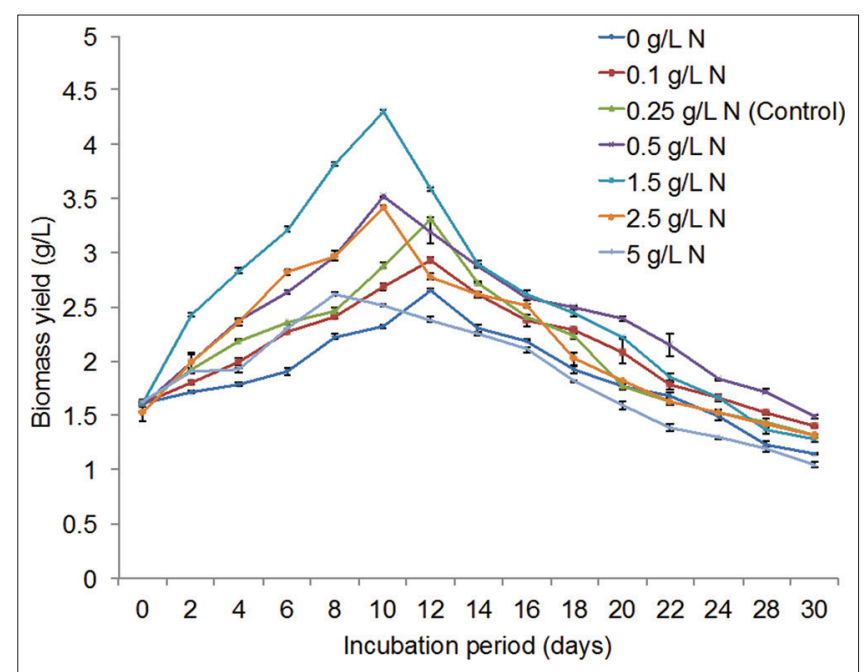

Figure 2: Biomass yield of $C$. aerea at different concentrations of nitrogen $(\mathrm{N})$

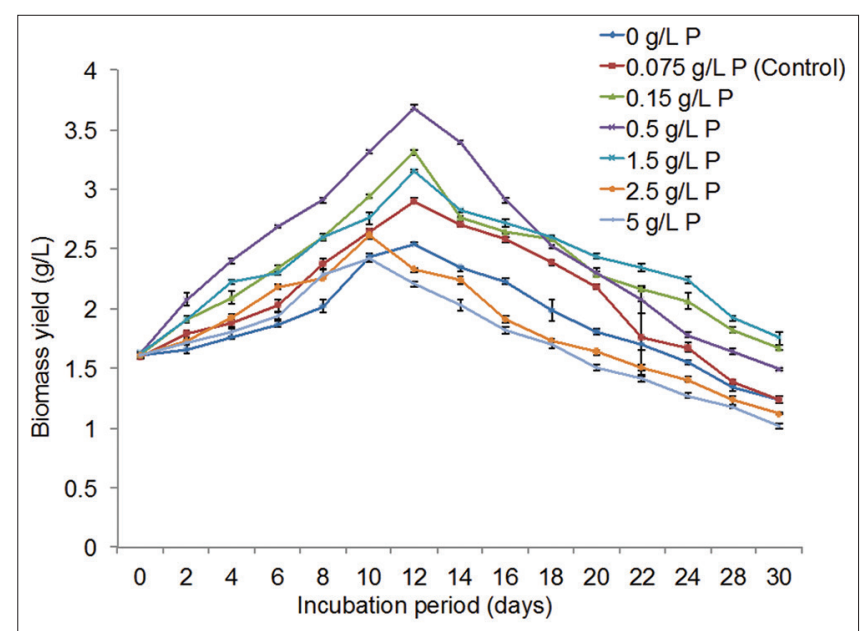

Figure 3: Biomass yield of $C$. aerea at different concentrations of phosphorus $(P)$

\section{RESULTS}

\section{Biomass Yield}

The effects of nitrogen, phosphorus, EDTA and $\mathrm{NaCl}$ on biomass yield is summarized in Figures 2-5. At the initial stage of cultivation, alga showed very slow growth but with time it changed significantly. The exponential growth period was observed at 8-10 days of cultivation. Interestingly after day 14 , the growth pattern was arrested with increasing concentrations of nutrients in the culture. Untreated culture of $C$. aerea showed highest biomass yield of $3.31 \pm 0.03 \mathrm{~g} / \mathrm{L}$ at 12 days of cultivation. The alga showed maximal biomass of $4.30 \pm 0.03 \mathrm{~g} / \mathrm{L}$ at $1.5 \mathrm{~g} / \mathrm{L}$ of nitrogen after 10 days incubation period. On day 12 , maximal biomass was harvested as $3.68 \pm 0.03 \mathrm{~g} / \mathrm{L}$ at $0.5 \mathrm{~g} / \mathrm{L}$ phosphorus. Filamentous chlorophytes showed positive growth with increasing concentration of EDTA. The highest biomass in the alga was obtained as $3.27 \pm 0.02 \mathrm{~g} / \mathrm{L}$ at $0.08 \mathrm{~g} / \mathrm{L}$ of EDTA after 10 days incubation. At very low

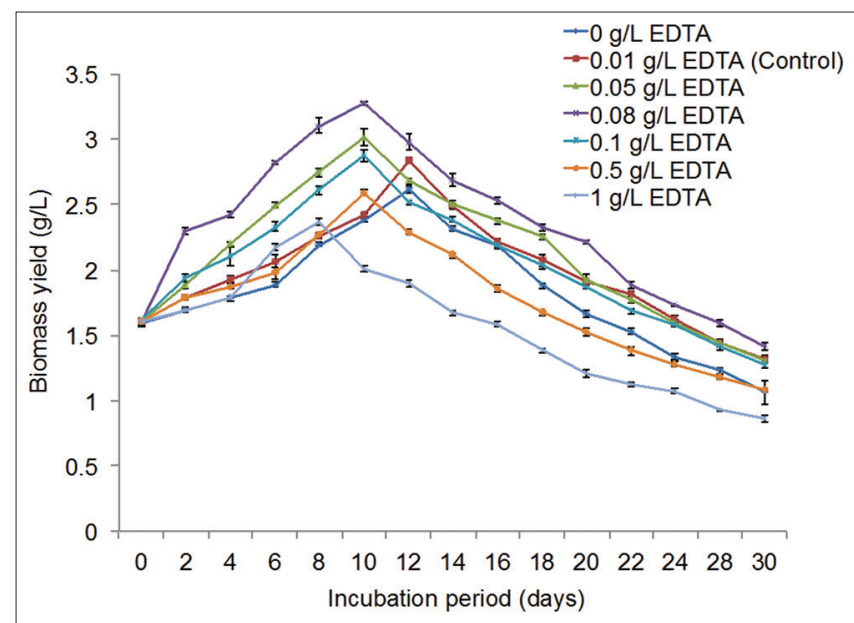

Figure 4: Biomass yield of $C$. aerea at different concentrations of EDTA

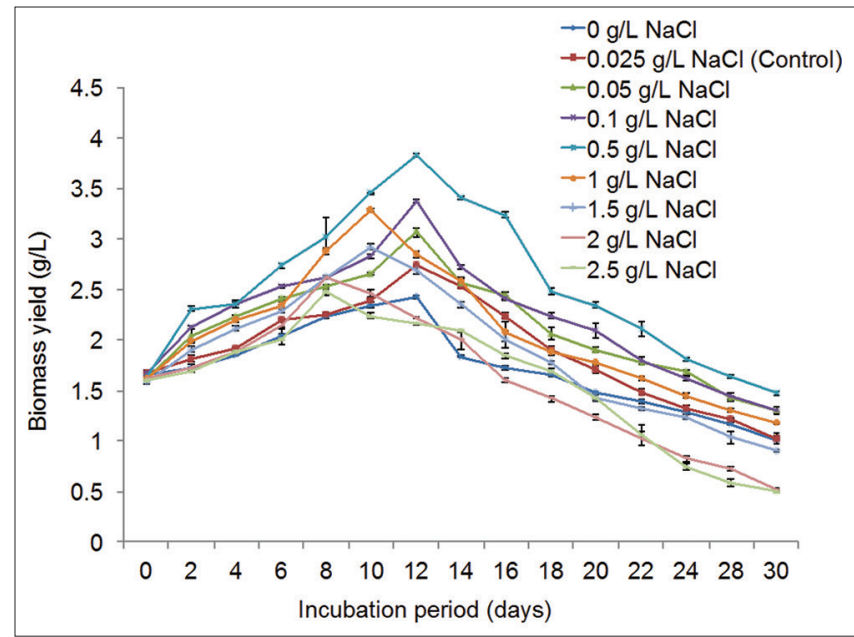

Figure 5: Biomass yield of $C$. aerea at different concentrations of $\mathrm{NaCl}$

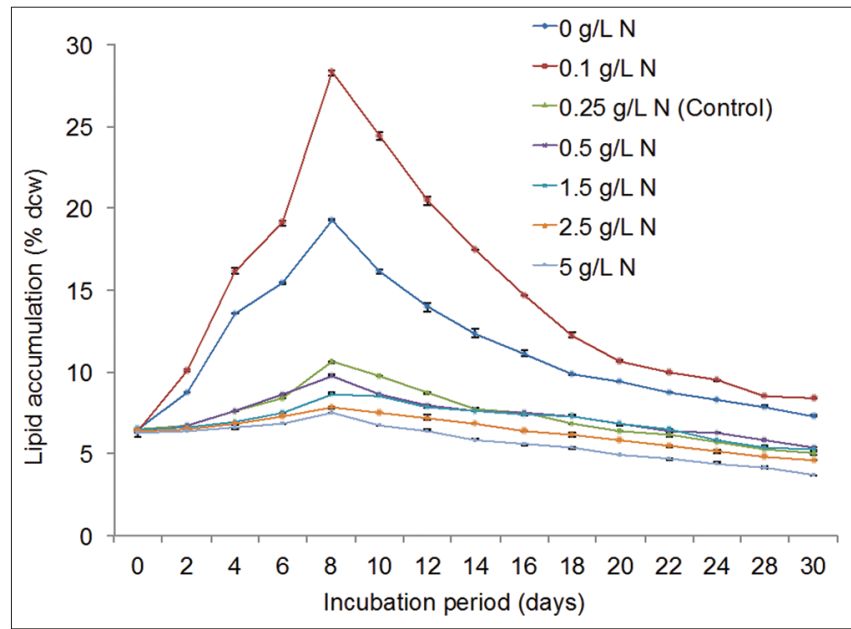

Figure 6: Lipid accumulation of $C$. aerea at different concentrations of nitrogen $(\mathrm{N})$

concentration of $\mathrm{NaCl}(0.5 \mathrm{~g} / \mathrm{L})$, the highest biomass of the alga was obtained as $3.83 \pm 0.03 \mathrm{~g} / \mathrm{L}$ after 12 days of incubation. 


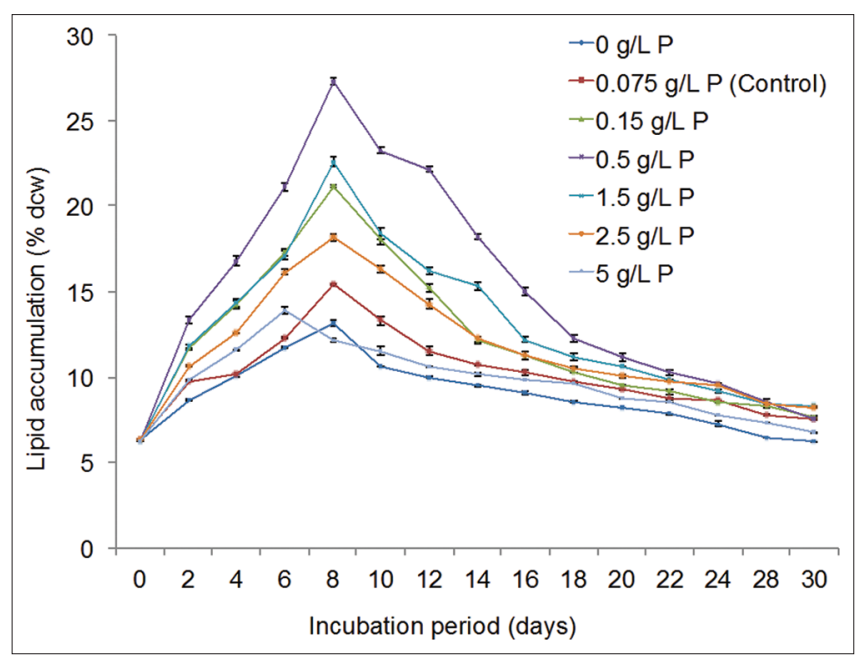

Figure 7: Lipid accumulation of $C$. aerea at different concentrations of phosphorus $(\mathrm{P})$

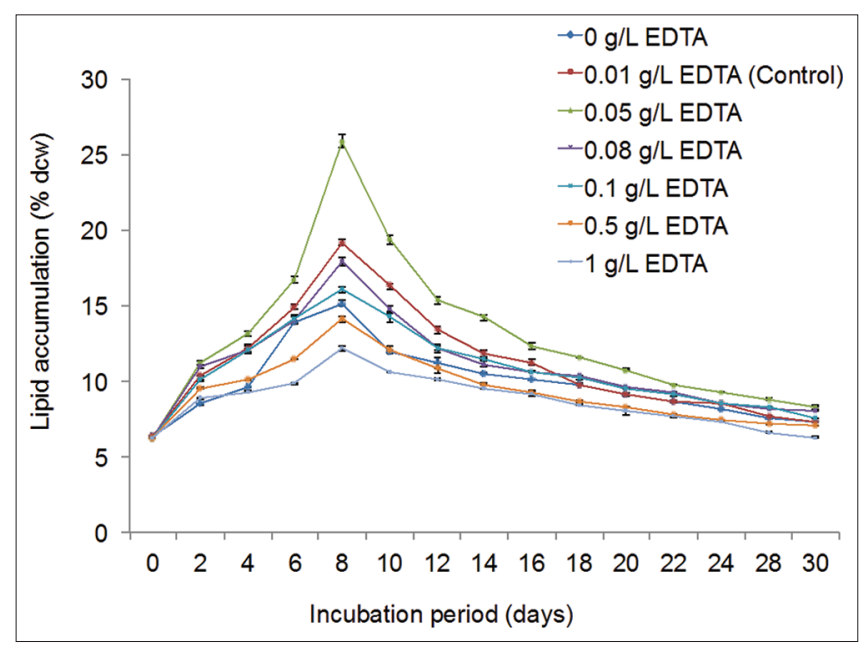

Figure 8: Lipid accumulation of $C$. aerea at different concentrations of EDTA

\section{Total Lipid Accumulation}

Figures 6-9 summarize the total lipid accumulation under different concentrations of nitrogen, phosphorus, EDTA and $\mathrm{NaCl}$. The results clearly demonstrated that the lipid accumulation in the macroalga increased drastically with the concentrations of nutrients on $10^{\text {th }}$ day of cultivation. The optimum lipid accumulation for the alga was noticed on day 8 of cultivation. In control condition, the highest lipid accumulation in C. aerea was $10.57 \pm 0.05 \%$ on $8^{\text {th }}$ day of cultivation. At $0.1 \mathrm{~g} / \mathrm{L}$ of nitrogen, C. aerea showed the maximum amount of total lipid accumulated as $28.27 \pm 0.04 \%$ after 8 days of incubation. On day 8 , the highest lipid accumulated in C. aerea was calculated as $27.30 \pm 0.37 \%$ at $0.5 \mathrm{~g} / \mathrm{L}$ of phosphorus. The alga showed maximum lipid accumulation of up to $25.86 \pm 0.77 \%$ (on $8^{\text {th }}$ day) at $0.05 \mathrm{~g} / \mathrm{L}$ of EDTA. On day 8, the alga showed highest lipid accumulation of $24.37 \pm 0.04 \%$ at $0.05 \mathrm{~g} / \mathrm{L} \mathrm{NaCl}$. The stationary phase for lipid accumulation was noticed after day 18 onwards.

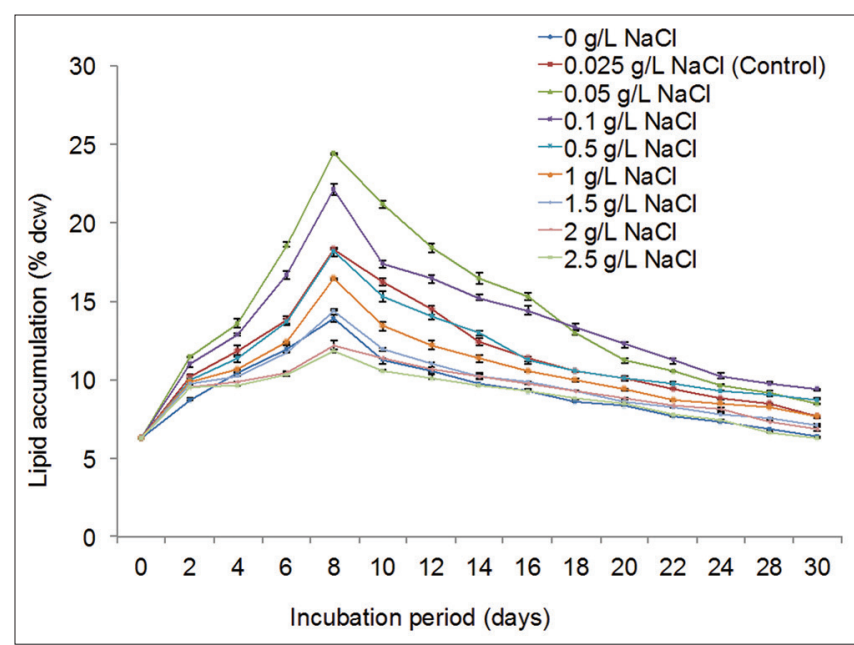

Figure 9: Lipid accumulation of $C$. aerea at different concentrations of $\mathrm{NaCl}$

\section{Changes of Fatty Acid Composition}

The fatty acid composition variations due to the different concentrations of nitrogen, phosphorus, EDTA and $\mathrm{NaCl}$ in the culture are listed in Table 1. Highest lipid containing cells from control and stress cultures were taken for FAME analysis and are presented in Table 1 . A total of seventeen fatty acids were obtained of which nine belong to saturated fatty acids, three to monounsaturated fatty acids and remaining were polyunsaturated fatty acids. The MUFA in this study increased when the concentrations of nitrogen was decreased. Similarly the MUFA was increased with increased concentrations of phosphorus, EDTA and $\mathrm{NaCl}$ in the culture. Interestingly the PUFA content was decreased with alterations of nutrients in the culture. The saturated fatty acids were increased in phosphorus and $\mathrm{NaCl}$ stress but decreased in nitrogen and EDTA stress. A significant increase of C15:0, Cl6:0, C16:1, C20:0, C20:1 and C22:0 were found in all treated conditions. In the filamentous alga, C17:0 was increased in phosphorus, EDTA and $\mathrm{NaCl}$ treated cells except nitrogen. Simultaneously, the decrease of Cl8:2 and C18:3 in nitrogen and EDTA treated conditions were studied. Furthermore, the absence of these fatty acids in phosphorus and $\mathrm{NaCl}$ treated cells were also observed. The absence of $\mathrm{C} 20: 3$ in nitrogen, phosphorus and $\mathrm{NaCl}$ treated cells and C20:4 in nitrogen and EDTA treated cells were observed. Lignoceric acid (C24:0) was decreased in nitrogen-starved cells whereas it increased in other nutritional stresses. Overall the productions of palmitic and palmitoleic acids were enhanced under nutrient stresses than the control. Phosphorus treatment showed better results for stearic acids and oleic acids than other fatty acids. EDTA stress resulted increase in palmitic, palmitoleic and stearic acids in the macroalga, whereas only palmitic and palmitoleic acids were increased under $\mathrm{NaCl}$ stress. Arachidic and paullinic acids were significantly increased in high lipid containing cells cultivated at $0.05 \mathrm{~g} / \mathrm{L}$ EDTA and $\mathrm{NaCl}$ respectively.

\section{DISCUSSION}

Environmental changes altered the biochemical composition as well as physiological changes including lipid accumulation in 
Table 1: FAME compositions of $C$. aerea

\begin{tabular}{|c|c|c|c|c|c|}
\hline \multirow[t]{2}{*}{ Fatty acids } & \multicolumn{5}{|c|}{ Fatty acid compositions (\%) } \\
\hline & Control & $0.1 \mathrm{~g} / \mathrm{L} \mathrm{N}$ & $0.5 \mathrm{~g} / \mathrm{L} \mathrm{P}$ & $0.05 \mathrm{~g} / \mathrm{L}$ EDTA & $0.05 \mathrm{~g} / \mathrm{L} \mathrm{NaCl}$ \\
\hline Lauric (12:0) & $0.95 \pm 0.35$ & $1.55 \pm 0.21^{\mathrm{a}}$ & ND & $0.75 \pm 0.21^{c}$ & $1.75 \pm 0.21^{\mathrm{ab}}$ \\
\hline Myristic (14:0) & $9.40 \pm 0.28^{\mathrm{ab}}$ & $6.90 \pm 0.28$ & $9.40 \pm 0.28^{b}$ & $0.50 \pm 0.28$ & $5.10 \pm 0.28^{b c}$ \\
\hline Pentadecylic (15:0) & $0.75 \pm 0.21$ & $1.70 \pm 0.28^{\mathrm{ab}}$ & $1.50 \pm 0.28^{c}$ & $1.25 \pm 0.35^{b}$ & $1.45 \pm 0.35$ \\
\hline Palmitic (16:0) & $49.10 \pm 0.28$ & $51.00 \pm 0.42^{\mathrm{a}}$ & $47.65 \pm 0.21^{\mathrm{ab}}$ & $43.00 \pm 0.42^{b}$ & $50.45 \pm 0.35^{a}$ \\
\hline Palmitoleic (16:1) & $8.5 \pm 0.28$ & $10.5 \pm 0.28^{c}$ & $12.35 \pm 0.35^{b c}$ & $9.75 \pm 0.21^{a b}$ & $12.65 \pm 0.35^{a}$ \\
\hline Margaric (17:0) & $0.70 \pm 0.14^{c}$ & $0.60 \pm 0.28$ & $1.00 \pm 0.28^{\mathrm{a}}$ & $0.75 \pm 0.21$ & $1.05 \pm 0.35^{b}$ \\
\hline Stearic (18:0) & $4.65 \pm 0.21$ & $3.70 \pm 0.28$ & $6.35 \pm 0.21^{b c}$ & $8.65 \pm 0.21^{\mathrm{ab}}$ & $4.40 \pm 0.28$ \\
\hline Oleic (18:1) & $16.95 \pm 0.63$ & $18.45 \pm 0.35^{b}$ & $17.75 \pm 0.21^{\mathrm{a}}$ & $16.60 \pm 0.42$ & $15.60 \pm 0.14^{c}$ \\
\hline Linoleic (18:2) & $4.65 \pm 0.63^{a}$ & $1.40 \pm 0.42$ & ND & $1.00 \pm 0.42^{b c}$ & ND \\
\hline$\alpha$-linoleic (18:3) & $1.50 \pm 0.42$ & $0.70 \pm 0.28^{\mathrm{ab}}$ & - & $1.95 \pm 0.21^{b c}$ & - \\
\hline Arachidic (20:0) & $0.60 \pm 0.28^{c}$ & $0.60 \pm 0.14^{a}$ & $0.60 \pm 0.28^{\mathrm{ab}}$ & $1.45 \pm 0.35^{\mathrm{a}}$ & $1.40 \pm 0.28^{c}$ \\
\hline Paullinic (20:1) & $0.35 \pm 0.07$ & $0.70 \pm 0.28$ & $0.40 \pm 0.28$ & $2.20 \pm 0.28^{\mathrm{ab}}$ & $1.05 \pm 0.49^{b}$ \\
\hline Dihomo- $\gamma$-linolenic $(20: 3)$ & $0.25 \pm 0.21^{b c}$ & ND & ND & $0.45 \pm 0.35$ & ND \\
\hline Arachidonic (20:4) & $0.40 \pm 0.28^{c}$ & ND & $0.20 \pm 0.14$ & ND & $1.00 \pm 0.42^{\mathrm{ab}}$ \\
\hline Eicosapentaenoic (20:5) & ND & $0.45 \pm 0.35^{b c}$ & $0.50 \pm 0.28$ & ND & $0.50 \pm 0.28^{c}$ \\
\hline Behenic (22:0) & $0.50 \pm 0.28$ & $0.65 \pm 0.35^{\mathrm{ab}}$ & $0.75 \pm 0.07$ & $0.50 \pm 0.28$ & $1.70 \pm 0.28^{c}$ \\
\hline Lignoceric (24:0) & $0.65 \pm 0.35$ & $0.35 \pm 0.35$ & $0.75 \pm 0.21$ & $1.50 \pm 0.28^{\mathrm{ab}}$ & $1.35 \pm 0.35^{b c}$ \\
\hline SFA & $67.30 \pm 0.26$ & $67.05 \pm 0.28$ & $68.00 \pm 0.22$ & $58.35 \pm 0.28$ & $68.65 \pm 0.30$ \\
\hline MUFA & $25.80 \pm 0.32$ & $29.65 \pm 0.30$ & $30.50 \pm 0.28$ & $28.55 \pm 0.30$ & $29.30 \pm 0.32$ \\
\hline PUFA & $6.80 \pm 0.38$ & $2.55 \pm 0.35$ & $0.70 \pm 0.21$ & $3.40 \pm 0.32$ & $1.50 \pm 0.35$ \\
\hline
\end{tabular}

Values expressed as mean \pm SD $(n=3)$. Superscript letters indicate significant differences $(p<0.05)$ for each treatment (ND- Not detected)

micro- and macroalgae. As shown in Figures 2-5 there is a slight decrease in the growth during the first day of inoculation, but the growth increased in the later stages of culture. From this, it was assumed that at the time of inoculation the cells began to adapt themselves to the new environment and assimilated almost no nutrients, which might suppress the cell division but promote the lipid productivity [21]. The similar observation was found in the report done by Valenzuela-Espinoza et al. [22]. The biomass yield in the present study was found to be maximum $(4.30 \pm 0.03 \mathrm{~g} / \mathrm{L})$ at $1.5 \mathrm{~g} / \mathrm{L}$ of nitrogen on $10^{\text {th }}$ day of cultivation. Hence the biomass with sodium nitrate $\left(\mathrm{NaNO}_{3}\right)$ as nitrogen source was significantly higher than others like phosphate, EDTA and $\mathrm{NaCl}$. Similarly, the maximum lipid accumulation in the macroalgal was $28.27 \pm 0.04 \%$ on day 8 , which was almost 3 times better than the control. From the above study it was confirmed that the alteration of nutrients were effective on growth of macroalgae and lipid accumulation. Similar results were obtained in previous works [23-26]. In the present study different nutritional combinations were applied on the green macroalga C. aerea and it was reported that highest lipid accumulation takes place at limited nitrogen. Reitan et al. cultured the microalgae at different culture media lacking nitrogen and observed the increase of lipid [27]. Nitrogen limited condition resulted increase of total lipid on day 17 in Chlorella vulgaris [28]. In our previous study, marine macroalga Rhizoclonium africanum showed maximum growth and lipid production at limited nitrogen [13]. Most of the works on biomass and lipid accumulation had been done using unicellular microalga [6, 28-32], while very few reports are available on filamentous macroalga $[12,14,33]$. In the present study different concentrations of four nutrients like nitrogen, phosphorus, EDTA and $\mathrm{NaCl}$ were introduced in the culture medium to study the growth pattern in terms of biomass yield and lipid accumulation in marine macroalga C. aerea.

The biosynthesis of lipid along with carbohydrate and protein was involved with many enzymatic reactions [21]. In the photosynthetic reaction the light energy is converted to chemical energy in the form of adenosine tri-phosphate (ATP) and reduced nicotinamide adenine dinucleotide phosphate (NADPH), which could then be used to convert $\mathrm{CO}_{2}$ and glyceraldehyde 3-phosphate $\left(\mathrm{G}_{3} \mathrm{P}\right)$ in the dark reaction. The $\mathrm{G}_{3} \mathrm{P}$ is the primary precursor for producing carbohydrates in the form of glucose and starch through a series of enzymatic reactions. The biosynthesis of lipid was done through a series of enzymatic reactions where glucose is converted to pyruvate (glycolysis). The pyruvate is the primary precursor, which forms acetyl CoA by the enzyme acetyl CoA carboxylase (ACCase) and the acetyl CoA is converted to malonyl CoA [34]. The nutrients may alter the formation of lipid biosynthesis through chemical changes. The fatty acids are formed from malonyl CoA (Figure 10). The lipid accumulation and fatty acid synthesis within the cell is due to the activation of ACCase enzyme [35-37]. The ACCase activity was regulated by the alkaline $\mathrm{pH}, \mathrm{NADPH}$ and $\mathrm{Mg}^{2+}$ [35]. The alkaline optimum $\mathrm{pH}$, increased NADPH and $\mathrm{Mg}^{2+}$ within the chloroplast stroma enhanced the ACCase activity. The nutrient deficient conditions changed the alkaline $\mathrm{pH}$, NADPH and $\mathrm{Mg}^{2+}$, which enhanced the activity of ACCase. The active ACCase then catalyzed the reaction of acetyl CoA to malonyl CoA and thus large quantity of fatty acids were formed. When photosynthesis proceeds, the chlorophyll within the chloroplast absorbs light and efflux protons $\left(\mathrm{H}^{+}\right)$from the stroma to the thylakoids. This results the increase of stromal pH from 7 to 8 . Then $\mathrm{Mg}^{2+}$ flowed into the stroma along with the $\mathrm{H}^{+}$ leading to an accumulation of $\mathrm{Mg}^{2+}$. When light interacts with the chlorophyll, the water splits to form electrons and these electrons are transported through the electron transport chain (ETC) to form NADPH with the help of enzyme Ferridoxin NADP reductase (FNR). This leads to the accumulation of stromal NADPH. This indicated that the biosynthesis of lipid is enhanced due to the influence of light and chlorophyll and other factors like alkaline $\mathrm{pH}, \mathrm{NADPH}, \mathrm{Mg}^{2+}$ and activity of ACCase. 


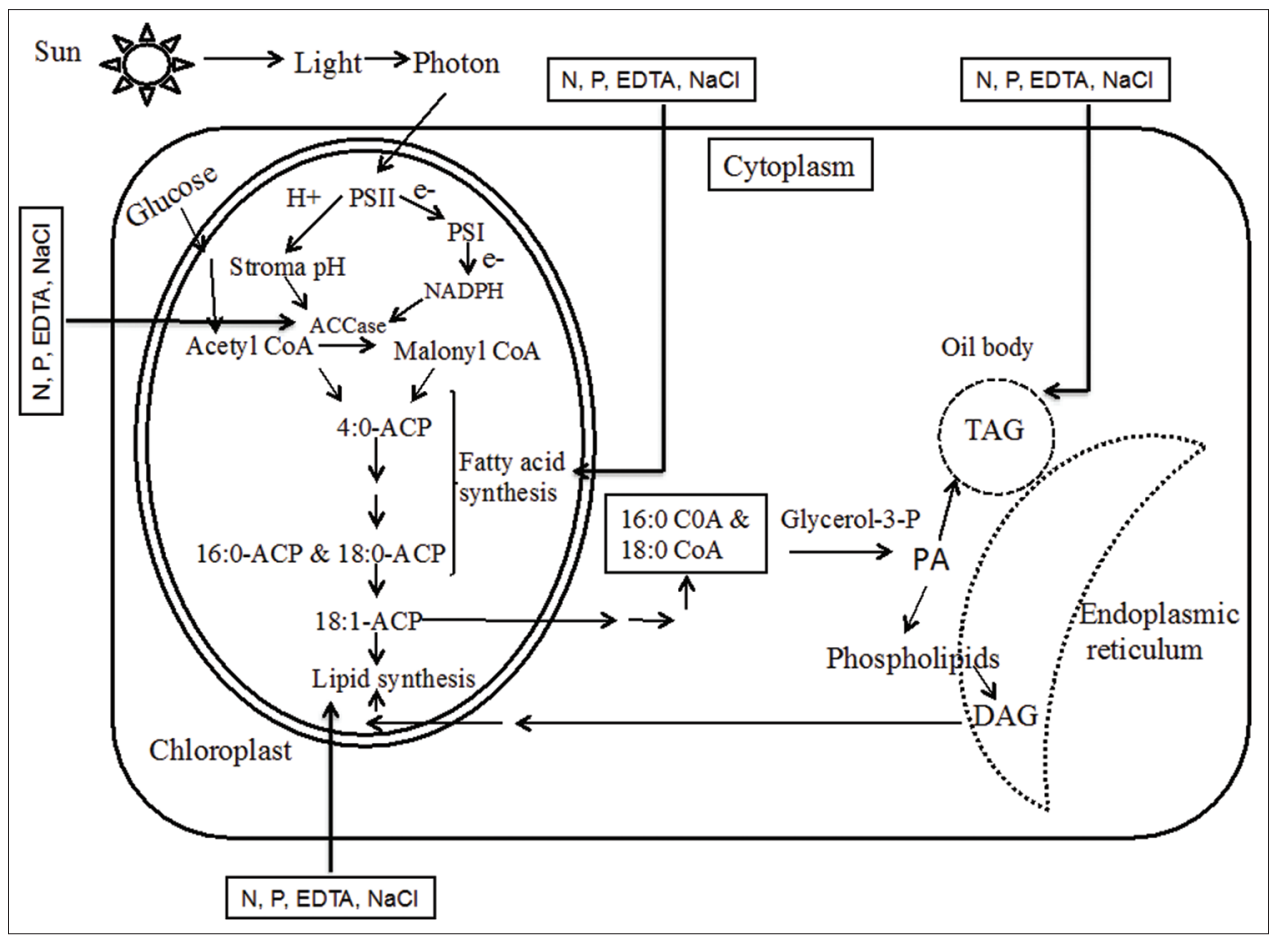

Figure 10: Lipid and fatty acid biosynthetic pathway under stress

The nutrient deficiency enhanced the production of Chlorophyll content including chlorophyll a, which might provide the more alkaline $\mathrm{pH}, \mathrm{Mg}^{2+}$ and NADPH to enhance ACCase activity. However more lipid accumulation takes place in nutrient limitation than the nutrient starvation. Sukenik and Livne has reported that the nitrogen limitation leads to a reduction of cellular abundance of ACCase with a decrease in the activity of the enzyme, but cell division almost ceased ensuing in the accumulation of lipid [37]. Therefore, it suggested that the optimal cultivation conditions including nutrient deficiency and accumulation lead to high biomass and high lipid productivity for biodiesel production.

\section{CONCLUSION}

From the above study it can be concluded that marine macroalga Chaetomorpha aerea showed extensive growth and lipid accumulation under nitrogen, phosphorus, EDTA and $\mathrm{NaCl}$ stress. The FAME composition also indicated its potentiality towards biodiesel application.

\section{ACKNOWLEDGEMENT}

Authors would like to thank Department of Botany, University of Calcutta for instrumental facilities. Authors would also like to thank Mrs. Mousumi Panda for English editing of this manuscript.

\section{REFERENCES}

1. Satpati GG, Gorain PC, Paul I, Pal R. An integrated salinity-driven workflow for rapid lipid enhancement in green microalgae for biodiesel application. RSC Advances. 2016;6;112340-112355.

2. Khotimchenko SV, Svetashev VI. Fatty acids of marine macrophytes.
Biologiya Morya. 1987;6:3-15.

3. Metzger P, Largeau C. Botryococcus braunii: a rich source of hydrocarbons and related ether lipids. Applied Microbiology and Biotechnology. 2005;66:486-496.

4. Hu Q, Sommerfeld M, Jarvis E, Ghirardi M, Posewitz M, Seibert M, Darzins A. Microalgal triglycerols as feedstocks for biofuel production: perspectives and advances, Plant Journal. 2008;54:621-639.

5. Nautiyal P, Subramanian KA, Dastidar MG. Production and characterization of biodiesel from algae. Fuel Processing Technology. 2014;120:79-88.

6. Satpati GG, Pal R. Rapid detection of neutral lipid in green microalgae by flow cytometry in combination with Nile red staining-an improved technique. Annals of Microbiology. 2015;65:937-949.

7. Converti A, Casazza AA, Ortiz EY, Perego P, Del Borghi M. Effect of temperature and nitrogen concentration on the growth and lipid content of Nannochloropsis oculata and Chlorella vulgaris for biodiesel production. Chemical Engineering Process. 2009;48(6):1146-1151.

8. Rodolfi L, Zittelli GC, Bassi N, Padovani G, Biondi N, Biondi G, Tredici MR. Microalgae for oil: strain selection, induction of lipid synthesis and outdoor mass cultivation in a low-cost photobioreactor. Biotechnology and Bioengineering. 2009;102:100-112.

9. Roleda MY, Slocombe SP, Leakey RLG, Day JG, Bell EM. Effects of temperature and nutrient regimes on biomass and lipid production by six oleaginous microalgae in batch culture employing a two-phase cultivation strategy. Bioresource Technology. 2013;129:439-449.

10. Chu FF, Chu NP, Shen XF, Lam PKS, Zeng RJ. Effect of phosphorus on biodiesel production from Scenedesmus obliquus under nitrogendeficiency stress. Bioresource Technology. 2014;152:241-246.

11. Satpati GG, Gorain PC, Pal R. Efficacy of EDTA and phosphorus on biomass yield and total lipid accumulation in two green microalgae with special emphasis on neutral lipid detection by flow cytometry. Advances in Biology. Hindawi. 2016;1-12.

12. Satpati GG, Pal R. Biochemical composition and lipid characterization of marine green alga U/va rigida- a nutritional approach. Journal of Algal Biomass Utilization. 2011; 2(4):10- 13.

13. Satpati GG, Kanjilal S, Prasad RBN, Pal R. Rapid accumulation of total lipid in Rhizoclonium africanum Kutzing as a biodiesel feedstock under nutrient limitations and the associated changes at cellular level. International Journal of Microbiology. Hindawi. 2015;1-13.

14. Gorain PC, Sengupta S, Satpati GG, Paul S, Tripathi S, Pal R. Carbon sequestration in macroalgal mats of brackish-water habitats in Indian 
Sunderbans: Potential as renewable organic resource. Science of the Total Environment. 2018;626:689-702.

15. Kumari P, Kumar M, Reddy CR, Jha B. Nitrate and phosphate regimes induced lipidomic and biochemical changes in the intertidal macroalga Ulva lactuca (Ulvophyceae, Chlorophyta). Plant Cell Physiology. 2014;55(1):52-63.

16. Kumar NJI, Kumar RN, Amb MK, Bora A, Chakraborty S. Variation of Biochemical Composition of Eighteen Marine Macroalgae Collected from Okha Coast, Gulf of Kutch, India. Electronic Journal of Environmental, Agricultural and Food Chemistry. 2010;9(2):404-410.

17. Venkatesalu V, Sundaramoorthy P, Anantharaj M, Chandrasekaran M, Senthilkumar A. Seasonal variation on fatty acid compositions of some marine macro algae from Gulf of Mannar Marine Biosphere Reserve, Southeast coast of India. Indian Journal of Geo-Marine Sciences. 2012;41(5):442-450.

18. Muralidhar AP, Syamala K, Prakash C, Kalidas C, Naik RP. Comparative Studies on Fatty Acid Composition of Three Marine Macroalgae Collected from Mandapam Region: South East Coast of India. World Applied Sciences Journal. 2010;11(8):958-965.

19. Bold HC. The morphology of Chlamydomonas chlamydogama, sp. nov. Bulletin of the Torrey Botanical Club. 1949;76(2):101-108.

20. Bligh EG, Dyer WJ. A rapid method of total lipid extraction and purification. Canadian Journal of Biochemistry and Physiology. 1959;37:911-917.

21. Lv JM, Cheng LH, Xu XH, Zhang L, Chen HL. Enhanced lipid production of Chlorella vulgaris by adjustment of cultivation condition. Bioresource Technology. 2010;101(17):6797-6804.

22. Valenzuela-Espinoza E, Millan-Nunez R, Nunez-Cebrero F. Biomass production and nutrient uptake by /sochrysis aff. Galbana (Clone T-ISO) culture with a low cost alternative to the $f / 2$ medium. Aquacultural Engineering. 1999;20:135- 147.

23. Brown MR, Jeffrey SW, Garland CD. Nutritional aspects of microalgae used in mariculture: a literature review. CSIRO (Australia) Marine Laboratories. 1989;205:44.

24. Gokpinar S. Effect of change of temperature on inorganic nitrogen assimilation of five important sea flagellate in aquaculture. Ph.D. thesis to the Dokuz Eylul University, Turkey; 1991.

25. Fidalgo JP, Cid A, Abalde J, Herrero C. Culture of the marine diatom Phaeodactylum tricornutum with different nitrogen sources: growth, nutrient conversion and biochemical composition. Cahiers De
Biologie Marine. 1995;36:165-173.

26. Xu N, Zhang X, Fan X, Han L, Zeng C. Effects of nitrogen source and concentration on growth rate and fatty acid composition of Ellipsiidion sp. (Eustigmatophyta). Journal of Applied Phycology. 2001;13:463-469.

27. Reitan KI, Rainuzzo JR, Olsen Y. Effect of nutrient limitation on fatty acid and lipid content of marine microalgae. Journal of Phycology. 1994;30:972-979.

28. Widjaja A. Lipid production from microalgae as a promising candidate for biodiesel production. Makara Technology, 2009;13(1):47-51.

29. Satpati GG, Mallick SK, Pal R. An alternative high throughput staining method for detection of neutral lipid in green microalgae for biodiesel application. Biotechnology and Bioprocess Engineering. 2015;20:1044-1055.

30. Dhup S, Kannan DC, Dhawan V. Growth, lipid productivity and cellular mechanism of lipid accumulation in microalgae Monoraphidium sp. following different phosphorus concentrations for biofuel production. Current Science. 2017;112(3):539-548.

31. Sonkar S, Mallick N. An alternative strategy for enhancing lipid accumulation in chlorophycean microalgae for biodiesel production. Journal of Applied Phycology. 2018;30:2179-2192.

32. Mohy El-Din SM. Accumulation of Lipids and Triglycerides in Isochrysis galbana Under Nutrient Stress. Applied Biochemistry and Biotechnology. 2017;189:359-373.

33. GeS, ChampagneP. Cultivation of the Marine Macroalgae Chaetomorpha linum in Municipal Wastewater for Nutrient Recovery and Biomass Production. Environmental Science and Technology. 2017;51(6):3558-3566.

34. Ohlrogge J, Browse J. Lipid biosynthesis. Plant Cell. 1995;7:957-970.

35. Livne A, Sukenik A. Lipid synthesis and abundance of acetyl CoA carboxylase in /sochrysis galbana (Prymnesiophyceae) following nitrogen starvation. Plant Cell Physiology. 1992;33:1175-1181.

36. Sasaki Y, Nagano Y. Plant acetyl CoA carboxylase: structure, biosynthesis, regulation and gene manipulation for plant breeding. Bioresource Technology and Biochemistry. 2004;68:1175-1184.

37. Sukenik A, Livne A. Variations in lipid and fatty acid content in relation to acetyl CoA carboxylase in the marine Prymnesiophyte /sochrysis galbana. Plant Cell Physiology. 1991;32:371-378. 